\title{
Perspectivas jurídicas da relação entre big data e proteção de dados
}

Mártin Marks Szinvelski

http://orcid.org/0000-0002-3078-2563

Taynara Silva Arceno ${ }^{I I}$

http://orcid.org/0000-0002-9524-2840

Lucas Baratieri Francisco III

http://orcid.org/0000-0001-8677-5955

${ }^{I}$ Universidade do Vale do Rio dos Sinos, São Leopoldo, RS, Brasil.

Mestrando em Direito Público pelo Programa de Pós Graduação em Direito. Bolsista CAPES/PROEX. Integrante do Grupo de Pesquisa CNPQ Estado, Administração Pública e Novas Tecnologias.

II Universidade do Vale do Rio dos Sinos, São Leopoldo, RS, Brasil.

Mestranda em Direito Público pelo Programa de Pós Graduação em Direito. Bolsista CAPES/PROEX. Integrante do Grupo de Pesquisa CNPQ Estado, Administração Pública e Novas Tecnologias.

III Universidade do Vale do Rio dos Sinos, São Leopoldo, RS, Brasil.

Acadêmico do curso de Direito. Integrante do Grupo de Pesquisa CNPQ Estado, Administração Pública e Novas Tecnologias. Bolsista PROBIC/FAPERGS.

\section{http://dx.doi.org/10.1590/1981-5344/4188}

O fenômeno do big data apresenta-se como efeito inevitável da quarta revolução industrial. Levando-se em consideração o incremento da quantidade de dados pessoais compartilhados diariamente na internet, o presente trabalho tem como objeto discutir a (in)compatibilização entre o big data e a proteção dos dados pessoais. Para que isso seja possível, se abordará a sociedade em rede, a resiginificação da privacidade e o próprio conceito de big data, de modo a apresentar, ao final da pesquisa exploratória, a conclusão. Ao Direito não cabe determinar o que a tecnologia deve ser, de modo a impedir o livre desenvolvimento tecnológico, medida que prejudicaria, sobretudo, o crescimento econômico do país. o papel do Direito no âmbito da relação entre big data e proteção dos dados pessoais associa-se mais a noção de "escudo", ou seja, como barreira frente à violação de 
direitos e o uso indiscriminado dos dados pessoais sem o consentimento dos titulares.

Palavras-chave: big data; privacidade; proteção de dados pessoais; tecnologia.

\section{Legal perspectives regarding big data and data protection's relationship}

Big data's phenomenon presents itself as inevitable effect of the fourth industrial revolution. Considering the increase of personal daily data shared on the Internet, this paper aims to discuss the (in)compatibility between the big data and the protection of personal data. For this, will be explained the network society, the redefinition of privacy and the concept of big data, to present, in the end of this exploratory research, the conclusion. Laws could not determine what the technology should be, to embarrass free technological development and the economic spread of the country. The role of law in the scope of the relationship between big data and protection of personal data is associated more with the notion of "shield", that is, as a barrier against the violation of rights and the indiscriminate use of personal data without consent of holders of them.

Keywords: big data; privacy; personal data protection; technology.

Recebido em 12.11.2019 Aceito em 13.11.2019

\section{Introdução}

Assim como ocorrera na Itália, nos albores da década de oitenta (FROSINI, 1981), a sociedade brasileira recebeu a oportunidade de regulamentar os instrumentos pelos quais a tutela dos dados pessoais deveria ser exercida, o qual realizou seguindo os moldes europeus (com exceção da consolidação do modelo de "autoridades independentes"). Os motivos foram contingenciais: não como medida preventiva, mas como impositiva da realidade cambiante. Além dos efeitos que o Regulamento Geral de Proteção de Dados da União Europeia (RGPD) impôs no ordenamento jurídico nacional, os vazamentos de informações pessoais que se tornaram recorrentes nos últimos anos, do qual o Caso Cambridge Analytica é o mais comentado e debatido, reativaram as propostas de 
regulações das quais é o resultado, a Lei Geral de Proteção de Dados Pessoais (Lei n. ${ }^{0}$ 13.709/2018) ${ }^{1}$. Nessa linha de raciocínio, o que resta evidenciado é que a ausência da tradição regulatória no tema não deve impedir a tutela eficaz de direitos fundamentais como a vida privada e a liberdade. Pelo contrário, deve representar uma vantagem a ser aproveitada, qual seja: a de verificar, quais instrumentos adotados em outros países tenderiam a conferir resultados satisfatórios à proteção de dados no Brasil. O desafio, nesse início de caminhada, está posto.

Por outra via, o momento reserva um modo di vivere interconectado, fator que complexifica a realidade. Se o volume de informação gerado e processado nos diferentes âmbitos teve como primeira consequência a necessidade de aplicar mecanismos informáticos ao tratamento de dados, agora, observa-se o incremento do volume de informações, da variedade de dados coletados, da velocidade da coleta e do processamento, aliado ao aspecto da veracidade da informação. Cuidase, portanto, do que se denomina big data, cuja implementação carrega consigo o desafio da proteção aos dados do cidadão, em especial pelo conteúdo econômico que estes possuem. ${ }^{2}$

A linha condutora da comunicação possui o ponto de partida teóricosociológico da sociedade em rede, em que se verifica o exercício de poderes fragmentados (não-monopolizados ou centralizados pelo Estado), por um lado; e, de outro, o componente tecnológico-informacional que conecta os interessados e permite a coleta de dados fornecidos direta ou indiretamente pelos internautas. O fato é que, após a obtenção da informação relevante, a proteção de dados (como direito autônomo ou como consequência do direito à privacidade) pode restar vulnerabilizada, de modo que a proposta de estudo se justifica com intenso vigor. Do ponto de vista metodológico3, trata-se de pesquisa desenvolvida por meio do método indutivo e da análise de bibliografia e de direito comparado. Com isso, busca-se descrever a sociedade em rede4 e o fenômeno do big data5, de modo a vinculá-los com a proteção de dados. Nesse sentido,

1 Mesmo após as adaptações introduzidas pela Lei n. ${ }^{0}$ 13.853/2019, a independência da autoridade ainda é ponto a ser discutido. (BRASIL, 2018).

2 Em relação à utilidade e à formação de um diagnóstico preciso da personalidade, das características pessoais e das preferências do titular dos dados, Limberger afirma que, atualmente, a exposição de dados pessoais ao público - como fotos e manifestações de pensamento, por exemplo - tornou-se um elemento relevante na formação da identidade da pessoa, de tal forma que as linhas que divisavam o público do privado passaram a serem tênues ou inexistentes e cuja consequência está relacionada à redução da autonomia do desenvolvimento de nossa própria personalidade. Nesse passo, verifica-se que a intimidade se

deslocou de um âmbito fechado do ser para o lado diametralmente oposto, à exterioridade, no que se denominou a socialização da intimidade. Cfr. LIMBERGER, 2016, p.60-63.

3 Parte-se de uma visão clara e objetiva de que cabe à pesquisa acadêmica em Direito estabelecer vínculos com a teoria do Direito e constatar os efeitos jurídicos que alcançam as novas tecnologias, e não apenas descrevê-las e relatar as novas possibilidades de aplicações na sociedade, em vista de uma absoluta incompetência material, na totalidade da metáfora processualística.

4 As referências são Stefano Rodotà, Antonio Enrique Peréz-Luño, Pierre Lévy e Manuel Castells.

5 Utiliza-se os seguintes autores: Neil Richards, Jonathan King e Ira S. Rubinstein, professores norteamericanos com destaque nas pesquisas sobre privacidade. A escolha desses professores justifica-se pela necessidade de renovação constante de referências. A indicação dos nomes, já na introdução, deve-se a fatores da exposição da metodologia. 
indaga-se: o relacionamento entre big data e a proteção de dados pessoais - em especial, o respeito ao direito à proteção de dados pessoais - é capaz de ser compatibilizado?

\section{2 sociedade tecnológica: a dinâmica das redes}

A popularização massiva da internet coloca em evidência não apenas a revolução tecnológica6, mas também a possibilidade de revolução jurídica?. Ao final, está-se diante da reformulação da relação qualificada da sociedade com ela mesma (PÉREZ LUÑO, 2014, p.10): se a sociedade é informatizada, as relações tendem a se estabelecer em rede e a proteção de direitos tenciona deslocar-se do espaço físico à proteção na virtualidade. ${ }^{8}$ A revolução da tecnociência, no dizer de Rodotà (2014, p.22), não redesenha somente a relação entre humano e não humano, mas afeta as dimensões do pós-humano. De fato, a internet viabilizou o surgimento da linguagem comum, em que os usuários tornam-se cocriadores. ${ }^{9}$ Mas não só isso: a internet tornou-se a plataforma sobre a qual se desenvolvem atividades de diferentes ramos. Nesse aspecto, ficar de fora da rede significa estar danosamente excluído da nova economia e socialmente alheio a dinâmica social. (CASTELLS, 2013, p.8). Da mesma maneira, a "revolução da internet", projeta o maior espaço público que a humanidade já conheceu, produzindo novas formas de relações institucionais, que contribuem para um possível constitucionalismo global. (RODATÀ, 2014, p.22). A internet que, no seu surgimento, apresentavase como tecnologia obscura, restrita e limitada, tornou-se o fator de impulso para uma nova forma de sociedade: a sociedade em rede, marcada pela relação humano-computador/dispositivos eletrônicos.

6 Veja-se o que informa Schwab sobre os efeitos específicos da implementação do big data: "Os riscos e as oportunidades do aproveitamento do grande volume de dados para a tomada de decisão são significativos. O estabelecimento da confiança nos dados e nos algoritmos usados para tomar decisões será vital. As preocupações dos cidadãos, no que diz respeito à privacidade e ao estabelecimento da responsabilidade comercial e nas estruturas legais, irão exigir ajustes na forma de pensar, bem como orientações para o uso e prevenção do perfil individual das pessoas (profiling) e consequências imprevistas". (SCHWAB, 2016, p. 137).

7 O fenômeno, por via de consequência, implica o recondicionamento da figura do Estado. A cibersociedade dispõe de formas de poder cujos contornos são invisíveis. Por um largo período de tempo, o exercício do poder esteve pautado pelo controle de diferentes aspectos da vida social; tais controles não fazem o sentido antes que faziam, dada a impossibilidade de controle da virtualidade. Conforme refere Bolzan de Morais, "o Estado de Direito se confronta com sua corrupção, por poderes selvagens". (BOLZAN DE MORAIS, 2017, p.84).

8 "O que caracteriza a atual revolução tecnológica não é a centralidade de conhecimentos e informação, mas a aplicação desses conhecimentos e dessa informação para a geração de conhecimentos e de dispositivos de processamento/comunicação da informação, em um ciclo de realimentação cumulativo entre a inovação e seu uso". (CASTELLS, 2017, p. 88.)

9 Trata-se de uma noção que implica a evolução da própria noção de computação, originalmente remetida a criação do microprocessador e anos depois com a conectividade de todos os microprocessadores em uma rede, o que por sua vez transformou o processamento e o armazenamento de dados centralizados em um sistema interativo e compartilhado de computadores. Além disso, ocorreu também evolução das telecomunicações com combinações de roteadores e computadores eletrônicos junto a novas conexões de transmissão. Importantes evoluções na optoeletrônica (transmissão por fibra ótica e laser) junto com a tecnologia de transmissão por pacotes digitais acarretaram em um aumento significativo na capacidade das linhas de transmissão. (CASTELLS, 2017, p.98-100). 
Nessa linha de ideias, segundo a visão de Lévy ${ }^{10}$, uma versão meramente funcional ou ergonômica da relação entre seres humanos e computadores não daria conta daquilo que está em jogo. Da mesma forma que as pessoas se apaixonam por uma casa, um carro ou uma moto, também se apaixonam por um computador, um programa ou uma linguagem de programação. A informática não intervém só na "ecologia cognitiva"11, mas também nos "processos de subjetivação individuais e coletivos". Essa dimensão implica numa nova técnica de produção e distribuição da informação e, no dizer de Vittorio Frosini, apresenta-se como uma neoforma de poder (1982, p.173).

A humanidade passa, à luz do que foi dito anteriormente, por uma revisitação antropológica, em razão de cada vez mais depender das aplicações tecnológicas: novas relações entre corpo e máquina se estabelecem. Nesse sentido, a intimidade adquire um novo conteúdo frente às novas técnicas de informática, de modo que o resguardo do cidadão com relação a dados informatizados deve acompanhar a evolução. Um cadastro pode armazenar um número inimaginável de informações, por isso, quando um indivíduo confia seus dados, seja a uma entidade pública ou privada, deve contar com uma tutela jurídica para que estes sejam utilizados corretamente (LIMBERGER, 2017, p.58).

Importantes acontecimentos, do ponto de vista da história americana, e que ilustram o debate proposto, demonstram que, no passado recente, o avanço tecnológico corroborou para a necessidade de editar legislações que, criticamente, podem ser denominadas de invasivas. Veja-se, primeiramente, o evento terrorista do 11 de setembro, em 2001, que levou os Estados Unidos da América a iniciarem a denominada "guerra ao terror", como apoio em legislação de características constitucionais questionáveis, tais como compartilhamento internacional de dados pessoais, biométricos e genéticos, além da assinatura do USA Patriot Act (UNITED STATES OF AMERICA, 2019, DEPARTMENT OF JUSTICE, 2019).

Na sequência, o caso Edward Snowden, em 2013, revelou programas secretos de vigilância conduzidos pela National Security Agency/Central Security Service (NSA/CSS) (UNITED STATES OF

${ }^{10}$ Estabelece Levy que, "(...) novas maneiras de pensar e de conviver estão sendo elaboradas no mundo das telecomunicações e da informática. As relações entre os homens, o trabalho, a própria inteligência dependem, na verdade, da metamorfose incessante de dispositivos informacionais de todos os tipos. Escrita, leitura, visão, audição, criação, aprendizagem são capturados por uma informática cada vez mais avançada". (LÉVY, 2011, p. 7).

11 O termo "Ecologia Cognitiva" foi apresentado por Pierre Lévy, em sua obra "Tecnologias da Inteligência" (1998), e foi embasado nas ideias de Bateson (1991) e Guattari (1989). Ecologia aponta para a existência de relações, diálogos e interações entre diferentes organismos, vivos ou não vivos. Cognitiva indica a relação com um novo conhecimento. Por isso, Ecologia Cognitiva significa as relações, os diálogos, as interações estabelecidas entre diferentes indivíduos, que possibilitam a construção de novos conhecimentos. Pierre Lévy aborda os termos "ciberespaço" e "cibercultura". O "ciberespaço" também chamado de rede é o novo meio de comunicação que tem origem na interconexão mundial de computadores. Os indivíduos navegam e se alimentam desse universo. Já o termo "cibercultura", especifica o conjunto de técnicas que se desenvolvem juntamente com o ciberespaço, isto é, técnicas materiais e intelectuais de práticas, de atitudes, de modo de pensamento e de valores que evoluem e se aperfeiçoam ao lado do ciberespaço. (LÉVY, 2011. p. 17). 
AMERICA. NATIONAL SECURITY AGENCY, 2019) os quais realizavam vigilância dos cidadãos, tanto norte-americanos quanto de outros países. O "boom" das últimas eleições norte-americanas, em 2016, tornou clara a utilização de análise comportamental de usuários do Facebook para o impulsionamento massivo de notícias falsas de acordo com os perfis dos usuários. Todos esses eventos envolveram, de algum modo, a tecnologia, a cibersegurança e violação a proteção de dados - e, por consequência, a intimidade. Os efeitos, portanto, estendem-se da esfera pessoal na direção da sociedade organizada, em que se verifica que a complexidade maior reside no desafio democrático de harmonização entre direitos e tecnologias, como alerta o Rodotà:

(...) desde esta perspectiva, es necesario profundizar en la relación entre democracia y tecnología. La tecnología es pródiga en promesas. Cada día ofrece más medidas para solucionar cualquier problema político, económico, social; sobre todo cuando se encuentran casos de tratamiento de datos personales. $Y$ esta situación técnica determina una tentación permanente por los políticos de delegar en la tecnología la solución de problemas difíciles (RODOTÀ, 2003, p.15-16).

Trata-se de uma preocupação que não vem de agora. O invisível sempre foi uma preocupação. Antes, o mercado, depois o Estado e, agora, possivelmente, a tecnologia12. A mineração de dados permite que as empresas e órgãos estatais descubram ou, até mesmo, induzam a ocorrência de fatos e padrões: este, sim, é um problema democrático. Não se saberá se a condução da sociedade está sendo desempenhada de maneira espontânea, como avanço cultural que lhe é própria ou como simulacro de uma condução orquestrada.

Por isso, Rodotà afirmava que se estava a viver a reinvenção da privacidade, pelos contornos ainda não definidos do avanço tecnológico e os efeitos na construção da identidade da pessoa (RODOTÀ, 2014). Desde a década de oitenta, surgiu a preocupação em regulamentar o acesso e às formas de tratamento de dados por sistemas informáticos. O avanço importante surgiu com a Diretiva 95/46/CE, que teve como objetivo unificar a proteção de dados pessoais em toda a União Europeia. O modelo europeu de proteção de dados pessoais evolui com o Regulamento Europeu 2016/679, que agora passa a tornar obrigatório o implemento de mecanismos que prestigiem a responsabilização proativa das organizações responsáveis pelo tratamento de dados pessoais. Como consequência de um mundo completamente interconectado, o Congresso Brasileiro, como forma de oferecer uma resposta às demandas crescentes de escândalos de vulneração de dados pessoais, aprovou a Lei n. 013.709 de agosto de

12 Nesse sentido, anota Bobbio, sobre a transformação da democracia que "(...)os estados tornaram-se cada vez maiores e sempre mais populosos, e neles nenhum cidadão está em condições de conhecer todos os demais, os costumes não se tornaram mais simples, tanto que os problemas se multiplicaram e as discussões são a cada dia mais espinhosas, as desigualdades de fortunas ao invés de diminuírem tornaram-se, nos estados que se proclamam democráticos (embora não no sentido rousseauniano da palavra), cada vez maiores e continuam a ser insultantes". (BOBBIO, 1986, p.42) 
2018, notadamente com o objetivo de guarnecer, no mínimo, alguns padrões de proteção de dados pessoais. Existe, é bem verdade, uma notável diferença entre a tradição europeia e a tradição brasileira no que concerne à temática da proteção de dados pessoais. Essa diferença existe, principalmente, porque a Europa discute e elabora legislações sobre o assunto desde a década de 1970, sendo que no Brasil, o emprego do termo "proteção de dados pessoais" ocorreu no ano de 2014, inserido no texto legal do Marco Civil da Internet, o que demonstra o "déficit" brasileiro de mais de 40 anos de envolvimento e debate sobre o tema.

Em que pese o país esteja apenas no início do percurso, o fato é que, da perspectiva teórica, ao menos, o Brasil possui marco regulatório da proteção de dados e engatinha no âmbito de garantir mecanismos de enforcement vinculantes nos âmbitos público e privado, tendo em conta a extrema necessidade de controle sobre o intenso fluxo de dados pessoais que ocorre diariamente na rede mundial de computadores. Nessa perspectiva, empresas detentoras de uma enorme quantidade de dados pessoais controlam o modo de vida das pessoas de tal forma, que as regras constritivas não são mais suficientes, sendo necessária a criação de garantias constitucionais para os direitos da rede.

\section{Big data e a proteção dos dados: entre a liberdade e o(s) paradoxo(s)}

A liberdade é uma conquista. A exposição nas redes de comunicação, que reflete essa liberdade, é, paradoxalmente, a fonte de monitoramento e controle de organizações (sejam estatais ou empresariais). De forma geral, as informações relativas ao indivíduo desde o seu nascimento até a morte, tendem a serem tratadas por algum meio digital, o que acaba por tornar o ser humano parte de um ciclo infinito de armazenamento e utilização de informações. Assim, o big data é utilizado para se referir a esses conjuntos de dados tão variados e coletados em grande quantidade que as tradicionais técnicas de análises de dados demonstram-se insuficientes. ${ }^{13}$

O termo big data foi utilizado inicialmente no início do século XXI por astrônomos e geneticistas, a partir do momento em que a memória dos computadores não era capaz de armazenar a enorme quantidade de informação disponível, obrigando, assim, a se pensar em novas formas e instrumentos a análise dos gigantes bancos de dados. Pode-se dizer que, apesar de ser objeto de ampla difusão, há na expressão certa ambiguidade, vagueza e imprecisão (GOMES, 2017, p.18) já que comporta diversas interpretações e significados - principalmente por ser utilizada por inúmeros setores.

13 O big data pode ser entendido, também, como a fonte mais poderosa para a mineração de dados, visto que trabalha com grandes volumes de infromações e demanda computadores mais rápidos e novas técnicas analíticas para descobrir correlações ocultas e surpreendentes, lançando dúvidas sobre a distinção entre dados pessoais e não pessoais, o que desafia a legislação internacional e nacional. (MENEZES NETO, 2016. p. 164-165) 
Mayer-Schonberger, da Universidade de Oxford, defende que a expressão "(...) big data refere-se a coisas que podem se fazer em grande escala, que não podem ser feitas em escala menor"14. Deveras, a imensa gama de sensores e câmeras e a multiplicidade de formas de acesso à rede torna o dado pessoal um grão de areia no deserto das informações em rede. Veja-se que o Instituto de Tecnologia \& Sociedade do Rio, ao apresentar uma tentativa de definição ao fenômeno, o enuncia como:

conjunto de dados cuja existência só é possível em consequência da coleta massiva de dados que se tornou possível nos últimos nos, graças à onipresença de aparelhos e sensores na vida cotidiana e do número crescente de pessoas conectadas a tais tecnologias por meio de redes digitais e também de sensores. (ITS, 2019)

De outra parte, Ira Rubinstein, da New York University School of Law (2013, p.4), torna factível que o big data deve ser apenas caracterizado. Nesse sentido, apresenta três características fundamentais. A disponibilidade de dados em grande escala, coletados não somente online (via computadores e redes sociais), mas através do uso de dispositivos móveis com recursos de rastreamento de localização e milhares de aplicativos (apps) que compartilham dados (IoT - internet das coisas), é a primeiro traço caracterizador; a alta velocidade de processamento e armazenamento, é o segundo elemento; a crescente utilização de novas ferramentas ou estruturas computacionais na verificação e tratamento de informações, apresenta-se como terceiro. Entretanto, a perspectiva adotada não exclui os malefícios da utilização da tecnologia. Richards e King (2013) estabelecem a transparência, a identidade e o poder como elementos paradoxais do fenômeno analisado. A promessa de utilização dos dados de forma transparente acaba entrando em choque como o fato das pessoas não saberem onde estarão os pontos coletores de informações pessoais ou os sensores, se em sites serão contabilizados os cliques do mouse e, até mesmo, em que medida será avaliada a interação em redes sociais.

A possibilidade de minimização da pessoa surge como segundo paradoxo. O big data pode ter como consequência a utilização do dado pessoal em ferramentas que incutam comportamentos não espontâneos nas pessoas. Trata-se da possibilidade de influenciar ou até restringir a edificação da identidade pessoal. Esse paradoxo conecta-se como o paradoxo do poder relativo ao controle das informações de pessoa ${ }^{15}$. À titulo comparativo, a linha trazida até aqui não é diferente da concepção de Rodotà, o qual vale a citação:

14 Tradução literal de: "big data refers to things one can do at a large scale that cannot be done at a smaller one" (MAYER-SCHONBERGER; CUKIER, 2013, p.6).

15 "Big data will create winners and losers, and it is likely to benefit the institutions who wield its tools over the individuals being mined, analyzed, and sorted. Not knowing the appropriate legal or technical boundaries, each side is left guessing. Individuals succumb to denial while governments and corporations get away with what they can by default, until they are left reeling from scandal after shock of disclosure. The result is uneasy, uncertain state of affairs that is not healthy for anyone and leaves individual rights eroded and our democracy diminished". (RICAHARDS; KING, 2013, p.45) 
Deve projetar-se também sobre os novos "Senhores da Informação" que, por meio das gigantescas coletas de dados, governam as nossas vidas. Em face de tudo isso, a palavra "privacy" evoca não apenas uma necessidade de intimidade, mas sintetiza as liberdades que nos pertencem no mundo novo onde vivemos. O próprio modo de ser desses sujeitos - chamados Amazon ou Apple, Google ou Microsoft, Facebook ou Yahoo! - mostra-nos uma presença de oportunidade para a liberdade e a democracia e de um poder soberano exercido sem controle sobre a vida de todos (RODOTÀ, 2015).

O big data é, perceptivelmente, mais invasivo, em vista da capacidade de conseguir coletar, armazenar e tratar de maneira mais detalhista e minuciosa as informações pessoais. ${ }^{16}$ Nesse ponto que reside, portanto, a aproximação gradativa com a pessoa, de modo a abrir espaço, de igual forma, para o seguinte questionamento: qual o impacto do big data na regulação da proteção de dados ${ }^{17}$

A noção de consentimento cristalizada na doutrina nacional e internacional possui como norte a ideia de manifestação livre, informada e inequívoca de concordância do titular com o tratamento de seus dados pessoais. No entanto, não há como anuir de forma livre, informada e inequívoca no contexto em que sensores, câmeras e demais dispositivos estão coletando dados pessoais de modo automático, uma vez que a compra dos produtos já poderá implicar o consentimento tácito da coleta de dados para o grande banco de dados. Possivelmente, se trabalhará, no futuro não tão distante, com a inversão da lógica civilista preponderante atualmente: ao invés de consentir, o titular deverá deixar de consentir ou eliminar dispositivos da vida cotidiana, porque não terá certeza do nível de captação de informações pessoais. Vale dizer, é possível se instaure a paranoia da vigilância, numa sociedade em que todos são vigiados e todos são vigias. Por isso, a transparência (i) de quais dados serão coletados, (ii) dos métodos na coleta de dados orientados de acordo com a finalidade anuída, (iii) dos programas de segurança e de correção de falhas da tecnologia adotados pela organização mostram-se o ideal democrático a ser perseguido em matéria de proteção de dados, por deixarem claro ao titular dos dados pessoais o objeto do consentimento, especialmente no contexto em que a tecnologia avança com intensa rapidez e utiliza os dados pessoais como "matéria prima", como registra Piñar Mañas:

(...) en realidad la mayor parte de las innovaciones tecnológicas que están produciéndose en la actualidad tienen directa (las más de las veces) o indirecta relación con el tratamiento de datos de carácter personal. Ya hace años se habló de las RFID, las cookies o más recientemente del cloud computing. Hablamos ahora también de big

\footnotetext{
16 Não há paralelo com as enquetes, censo demográficos, pesquisa de consumo.

17 A LGPD estabelece como fundamentos de aplicabilidade da lei o respeito à privacidade, a autodeterminação informativa, a liberdade de expressão, de informação, de comunicação e de opinião, a inviolabilidade da intimidade, da honra e da imagem, o desenvolvimento econômico e tecnológico e a inovação, a livre iniciativa, a livre concorrência e a defesa do consumidor e os direitos humanos, o livre desenvolvimento da personalidade, a dignidade e o exercício da cidadania pelas pessoas naturais.
} 
data, Internet de las cosas, wearables, bitcoin, block chain, robótica, drones, inteligencia artificial, gene drive technology, data driven innovation, ciudades inteligentes... Cualquiera de estos conceptos es imposible sin el uso de datos (2017, p.70).

Desse modo, a pergunta em torno do relacionamento entre proteção de dados e o big data não pode ser remetida ao simplismo teórico que indaga, ao fim da frase, "como o Direito deve regular?". Pelo contrário, deve haver o debate anterior, no sentido de saber o se o Direito possui capacidade e legitimidade de regular ou se a matéria já está regulada. Reconhecer a complexidade da sociedade implica descobrir, na sequência, que a realidade da decisão é contingencial e implica o risco de decidir equivocadamente. Por isso, a ideia que se procura estabelecer se refere à noção de impacto no que cabe ao Direito regular - os direitos das pessoas - e o relacionamento entre regulação estabelecida e a tecnologia. Não cabe o Direito dizer o que é tecnologia deve ser, mesmo reconhecendo que o fetiche regulatório ou normativista segue presente na tradição brasileira, mais para atrapalhar do que para auxiliar os profissionais.

Deve-se reconhecer, portanto, que o Direito sempre esteve direcionado a regular fatos da vida de pessoas, e jamais deve abandonar essa função. A diferença está muito bem delineada na perspectiva futura que o Direito passará a ingressar - agora, sem retorno - na "regulação"(?) da tecnologia, que é produto do pensamento humano. Do ponto de vista filosófico, não existem limites à imaginação humana e, portanto, a tecnologia a ser criada. Terminologicamente, não haveria possibilidade de regulá-la, mas, sim, mediar, de modo que o Direito se torne o que sempre foi, especialmente após a Revolução Francesa, uma barreira à violação de direitos e escudo contra o arbítrio, que se apresenta potencialmente no despotismo tecnológico (senhores da informação), de um lado; e os vulneráveis cidadãos-consumidores, de outro.

O big data é, antes, tecnologia. A proteção de dados deve ser articulada com vistas à utilização dos dispositivos tecnológicos de forma compatibilizada entre as diversas aplicações a serviço do ser humano, mas que leve em conta a potencialidade do dano: a ausência de transparência que leva ao consentimento não informado ou a coleta não autorizada de dados pessoais; a noção de resguardo à dignidade humana e o livre desempenho da personalidade e da autodeterminação informativa, na construção da identidade própria da pessoa e não identidade que menospreza a singularidade de cada um; e a ideia de democracia e poder, no sentido de coibir o monopólio de informações e a utilização abusiva dos dados pessoais para finalidades deturpadas e não compatíveis com a construção republicada de uma sociedade global e pautada pelo respeito intercultural.

\section{Conclusão}

Foi investigada a compatibilização entre o big data e a proteção de dados pessoais. A análise leva, quase que necessariamente, ao reconhecimento do fato de que a mundialização do mundo proporcionada 
pela internet teve como consequência singular a mutação do que se conhece como intimidade. Para o bem ou para o mal, a inovação tecnológica veio para ficar e, o big data, produto desta contingência, apresenta-se como aplicação inevitável de organizações públicas e privadas. Ocorre que o dado pessoal (a informação que permite identificar o titular do dado) ocupa centralidade na maioria das inovações. Deveras, se a tecnologia se apresenta, em tese, a serviço do ser humano, a ampliação da capacidade tecnológica acarreta, também, a aproximação da tecnologia com os destinatários das funcionalidades. Como se fossem as faces pertencentes à mesma moeda, deve-se não apenas reconhecer a qualidade do avanço tecnológico e os benefícios da utilização do big data, mas também os riscos da utilização com finalidades não democráticas.

Por isso, considera-se fundamental o alerta relativo ao interrelacionamento entre os três paradoxos do big data: a transparência, a identidade e o poder. A razão da preocupação guarda relação com o caráter mais invasivo que proporciona o big data: não havendo transparência de onde, quando e como os dados são coletados, não haveria condições do titular do dado pessoal consentir com o tratamento e a corresponde utilização das informações. Para, além disso, a utilização desfocada tende a acirrar o risco à democracia - e aos contornos da soberania popular, lócus do qual advém a legitimidade do poder do exercício simbólico da força. A centralidade do tema dos paradoxos é relevante, no atual contexto, em razão da sociedade em rede apresentar a informação como neoforma de poder, como já dizia Frossini (1982, p.173). Ao Direito não cabe outra coisa senão mediar o processo de relacionamento entre tecnologia (no caso, big data) e a proteção da pessoa (âmbito no qual se insere a proteção de dados pessoais). Não existem freios à capacidade humana de se reinventar e de transformar areia em matéria prima, e não há motivo pelo qual o Direito possa servir de instrumento para o atraso, o totalitarismo e à servidão. O pensamento de Hannah Arendt, ao escrever que "solo l'immaginazione ci permette vere le cose sotto Il loro vero aspecto, di porre a distanza ciò che è troppo vicino in modo da comprenderlo senza parzialità né pregiudizi, di colmare l'abisso che ci separa da ciò che troppo lontano in modo da comprenderlo como se ci fosse familiare" (1985, p.110), pousa como fechamento da presente comunicação, no sentido de ser a imaginação algo que torna o distante algo familiar, e o que, talvez, torne "o futuro imaginado", pautado pela proteção do que é humano, possível.

\section{Referências}

ARENDT, Hannah. La disobbedienza civile e altri saggi. Milano: Giuffré, 1985.

BOBBIO, Norberto. O futuro da Democracia. Tradução de Marco Aurélio Nogueira. Rio de Janeiro: Paz e Terra, 1986.

BOLZAN DE MORAIS, José Luis. O fim da geografia institucional do Estado. A "crise" do estado de direito! In: STRECK, Lenio Luiz (orgs.). 
Constituição, Sistemas Sociais e Hermenêutica, n.13. Porto Alegre: Livraria do Advogado, 2017. p.77-97.

CASTELLS, Manuel. A galáxia da internet: reflexões sobre a internet, os negócios e a sociedade. Rio de Janeiro: Zahar, 2013.

BRASIL. Lei n.o 13.709, de 14 de agosto de 2018. Lei Geral de Proteção de Dados Pessoais (LGPD). Disponível em:

http://www.planalto.gov.br/ccivil 03/ ato2015-

2018/2018/lei/L13709compilado.htm. Acesso 16 jul. 2019.

CASTELLS, Manuel. A sociedade em rede. 18. ed. São Paulo: Paz e Terra. 2017.

FROSINI, Vittorio. Cibernética, derecho y sociedad. Madrid: Tecnos, 1982.

FROSINI, Vittorio. La protezione della riservatezza nella società informatica. Rivista Informatica e diritto, VII Annata, v. 7, n. 1, 1981.

GOMES, Rodrigo Dias de Pinho. Big data: desafios à tutela da pessoa humana na sociedade da informação. Rio de Janeiro: Lumen Juris, 2017.

ITS Rio. Big Data no projeto Sul Global: Relatório sobre estudos de caso. Disponível em: https://itsrio.org/wpcontent/uploads/2016/03/ITS Relatorio Big-Data_PT-BR v2.pdf.

Acesso em: 03 jul. 2019.

LÉVY, Pierre. As tecnologias da inteligência. 2.ed. Rio de Janeiro: Ed. 34. 2011.

LÉVY, Pierre. Cibercultura. 3.ed. São Paulo: Ed.34, 2011.

LIMBERGER, Têmis. Cibertransparência: informação pública em rede: a virtualidade e suas repercussões na realidade. Porto Alegre: Livraria do Advogado, 2016.

LIMBERGER, Têmis. O direito à intimidade na era da informática: A necessidade de proteção dos dados pessoais. Porto Alegre: Livraria do Advogado, 2007.

MAYER-SCHONBERGER, Viktor; CUKIER, Kenneth. Big data: a Revolution that will transform how we live, work, and think. New York: Houghton Mifflin Harcourt, 2013.

MENEZES NETO, Elias Jacob de. Surveillance, democracia e direitos humanos: os limites do estado na era do Big Data. Tese de Doutorado. UNISINOS. Programa de Pós-Graduação em Direito. São Leopoldo. 2016. PÉREZ LUÑO, Antonio-Enrique. Teledemocracia, ciberciudadania y derechos humanos. Revista Brasileira de Políticas Pública, Brasília, DF, v.4, n.2, p.10, 2014.

PIÑAR MAÑAS, José Luis. Sociedad, innovación y privacidad. Información Comercial Española, ICE: Revista de economía, Madrid, n. 897, p.70, jul./ago, 2017. 
RICAHARDS, Neil M.; KING, Jonathan H. Three Paradoxes of Big Data. Stanford Law Review Online, v. 66, Sept. 3, 2013. Disponível em: https://www.stanfordlawreview.org/online/privacy-and-big-data-threeparadoxes-of-big-data/. Acesso em: 30 nov. 2019.

RODOTÀ, Stefano. Democracia y protección de datos. Cuadernos de Derecho Público, Bogotà, n. 19-20, p.15-26, mayo-dic., 2003.

RODOTÀ, Stefano. El derecho a tener derechos. Madrid: Trotta, 2014. RODOTÀ, Stefano. Por que é necessária uma Carta de Direitos da Internet?. Civilistica.com, Rio de Janeiro, n. 2, jul./dez.2015. Disponível em: http://civilistica.com/por-que-e-necessaria-uma-carta-de-direitos-dainternet/. Acesso em: 20 jun. 2019.

RUBINSTEIN, Ira S. Big Data: The end of privacy or a new beginning?, International Data Privacy Law, v.3, n. 2, 2013. Disponível em: https://academic.oup.com/idpl/article/3/2/74/709082. Acesso em: 30 nov. 2019.

SCHWAB, Klaus. A quarta revolução industrial. São Paulo: Edipro, 2016. UNITED STATES OF AMERICA. Department of Justice: What is the USA Patriot Web, 2019. Disponível em:

https://www.justice.gov/archive/ll/highlights.htm. Acesso: 30 jun. 2019. UNITED STATES OF AMERICA. National Security Agency, 2019. Disponível em: https://www.nsa.gov/. Acesso em: 30 jun. 2019. 